\title{
Quantitative method for determining serum alkaline phosphatase isoenzyme activity: estimation of intestinal component
}

\author{
M J PEAKE, M PEJAKOVIC, G H WHITE \\ From the Department of Biochemistry and Chemical Pathology, Flinders Medical Centre, Bedford Park, South \\ Australia
}

SUMMARY Intestinal alkaline phosphatase activity was measured using levamisole inhibition, and $\stackrel{\vec{\sim}}{\sim}$ results were compared with a previously reported method using L-phenylalanine. Sixty two per cent ĩ intestinal, $39 \%$ placental, and $1.3 \%$ of either bone or liver alkaline phosphatase activity remained $\mathrm{N}$ when alkaline phosphatase activity was inhibited in a 2-amino-2-methyl-1-propanol (AMP) buffer 은 reagent system with $10 \mathrm{mmol} / 1$ levamisole (final assay concentration $8 \cdot 1 \mathrm{mmol} / \mathrm{l}$ ). The assay $\vec{T}$ imprecision (SD) was $0.6 \mathrm{U} / 1$ compared with $3.9 \mathrm{U} / 1$ using L-phenylalanine for specimens with total $\frac{\Phi}{O}$

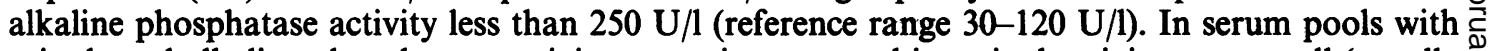
raised total alkaline phosphatase activity errors in recovered intestinal activity were small (usually less than $3 \mathrm{U} / \mathrm{l}$ ) when intestinal alkaline phosphatase was added. Much larger errors and many $\vec{\bullet}$ underestimated results were found using L-phenylalanine. For non-haemolysed specimens it is $\underset{\infty}{\infty}$ concluded that an assay based on levamisole inhibition provides a better measure of intestinal i alkaline phosphatase activity than L-phenylalanine.

A raised serum alkaline phosphatase activity [EC 3.1.3.1] is a common finding in the clinical chemistry laboratory. In a proportion of such cases either the tissue source of the enzyme activity is not identifiable by the clinician, or the contribution from one or more pathological processes is masked. ${ }^{1}$ A method for separately quantifying bone, liver, intestinal and placental alkaline phosphatase isoenzyme activities has, however, recently been described. ${ }^{2}$

This method determines the residual serum alkaline phosphatase activity following various inhibitory treatments, with individual isoenzymes being affected in a predictable manner. Each isoenzyme activity present in the original specimen is then quantified by insertion of the residual activities into an appropriate algorithm. Because four separate activity measurements must be made, it is important that the precision and accuracy of each quantitative step is optimised so that the cumulative error on the calculated isoenzyme activities is minimised. One of the inhibitors used is L-phenylalanine, a non-competitive inhibitor of intestinal alkaline phosphatase. The activity of the intestinal component is computed from activities remaining in the presence and absence of $L$ -

Accepted for publication 11 August 1987 phenylalanine, with a correction being made for its $\frac{2}{1}$ partial inhibition of the other isoenzymes. In routine $\stackrel{\varrho}{?}$ use, however, we have noticed that the reported $\overrightarrow{\vec{O}}$ method may underestimate intestinal alkaline phosphatase activity when total alkaline phosphatase activity is very high.

Levamisole, a phenylimidazothiazole compound, has been reported to act in the opposite manner to $L-\frac{O}{-}$ phenylalanine by inhibiting non-intestinal alkaline? phosphatase isoenzyme activity, while leaving that of the intestinal component largely unaffected. ${ }^{3} \mathrm{We}$ therefore investigated whether levamisole and a을 similar compound, bromotetramisole, ${ }^{3}$ may be better reagents than L-phenylalanine for measuring intestinal alkaline phosphatase activity by permitting $\mathrm{a}_{\mathrm{N}}$ more direct measurement of the activity of the desired or component.

\section{Material and methods}

Total, placental, and intestinal alkaline phosphatase $\frac{0}{\Phi}$ activities (using L-phenylalanine) were measured as $\stackrel{9}{-}$ previously reported. ${ }^{2}$ Levamisole (Sigma, molecular 0 weight 240.8 daltons) was accurately weighed out ando오 dissolved in 2-amino-2-methyl-1-propanol (AMP) buffer from single phial Monotest alkaline phos- $\mathbb{\mathbb { D }}$ 
phatase kits (Boehringer, West Germany) at concentrations of 5,10 , and $20 \mathrm{mmol} / \mathrm{l}$. Bromotetramisole (Janssen Pharmaceutica Belgium molecular weight 372.2 daltons and Sigma molecular weight 373.2 daltons) was dissolved in AMP buffer at concentrations of $0.27 \mathrm{mmol} / 1(0.01 \%)$ and $1.34 \mathrm{mmol} / 1$ $(0.05 \%)$. Assays were performed on a Cobas Bio centrifugal analyser (Roche Instruments, Basel, Switzerland) using the instrument settings shown in table 1 . Extracts of intestinal alkaline phosphatase activity were prepared and measured as previously described. ${ }^{4}$

\section{Results}

\section{LEVAMISOLE OR BROMOTETRAMISOLE}

Inhibition of alkaline phosphatase activity by levamisole and bromotetramisole has previously been reported in assay systems incorporating $\mathrm{N}$-ethylaminoethanol(NEAE) buffer-the placental and intestinal isoenzymes being the most resistant to inhibition. ${ }^{3}$ We tested these reagents in our assay system, using AMP buffer, at reagent concentrations designed to inhibit maximally bone and liver activity

Table 1 Reaction conditions on Cobas Bio for measuring intestinal alkaline phosphatase isoenzyme activity using levamisole

\section{Instrument settings}

\begin{tabular}{rlr}
\hline 1 & Units & $\mathrm{U} / 1$ \\
2 & Calculation factor & 2688 \\
3 & Standard 1 concentration & 0 \\
4 & Standard 2 concentration & 0 \\
5 & Standard 3 concentration & 0 \\
6 & Limit & $1 \cdot 5$ \\
7 & Temperature $\left({ }^{\circ} \mathrm{C}\right)$ & 37 \\
8 & Type of analysis & 2 \\
9 & Wavelength $(\mathrm{nm})$ & 405 \\
10 & Sample volume $(\mu \mathrm{l})$ & 5 \\
11 & Diluent volume $(\mu \mathrm{l})$ & 30 \\
12 & Reagent volume $(\mu \mathrm{l})$ & 150 \\
13 & Incubation time $($ seconds) & 120 \\
14 & Start reagent volume $(\mu \mathrm{l})$ & 0 \\
15 & Time of first reading (seconds) & 30 \\
16 & Time interval (seconds) & 10 \\
17 & Number of readings & 20 \\
18 & Blanking mode & 1 \\
19 & Printout mode & 1 \\
\hline
\end{tabular}

Table 2 Percentage activity remaining for each isoenzyme after inhibition with levamisole or bromotetramisole

\begin{tabular}{|c|c|c|c|c|}
\hline \multirow[b]{3}{*}{ Isoenzyme } & \multicolumn{4}{|c|}{ Percentage activity remaining } \\
\hline & \multicolumn{3}{|c|}{ Levamisole } & \multirow{2}{*}{$\begin{array}{l}\text { Bromotetramisole } \\
0.27 \mathrm{mmol} / \mathrm{l}\end{array}$} \\
\hline & $5 \mathrm{mmol}$ & $110 \mathrm{mmol} / \mathrm{l}$ & $20 \mathrm{mmol} / \mathrm{l}$ & \\
\hline $\begin{array}{l}\text { Bone } \\
\text { Liver } \\
\text { Intestinal } \\
\text { Placental }\end{array}$ & $\begin{array}{l}2 \cdot 0 \\
2 \cdot 0 \\
75 \\
53\end{array}$ & $\begin{array}{l}1 \cdot 3 \\
1 \cdot 3 \\
62 \\
39\end{array}$ & $\begin{array}{l}0 \cdot 7 \\
0 \cdot 7 \\
47 \\
25\end{array}$ & $\begin{array}{l}\sim 4 \\
\sim 4 \\
\sim 90 \\
\sim 90\end{array}$ \\
\hline
\end{tabular}

while minimally reducing intestinal activity. The maximum solubility of bromotetramisole was about 0.27 $\mathrm{mmol} / 1(0.01 \%)$; the Sigma preparation was slightly more soluble. Bromotetramisole was dissolved in glass tubes because the reagent partially adhered to plastic. Following inhibition with $0.27 \mathrm{mmol} / \mathrm{l}$ bromotetramisole about $90 \%$ of intestinal activity remained, and $3-5 \%$ of bone and liver alkaline phosphatase activity. Unfortunately, an attempted five-fold increase in bromotetramisole concentration minimally increased the inhibition of the bone and liver isoenzyme activity, due mainly to its low solubility. In contrast, levamisole was readily soluble to at least $20 \mathrm{mmol} / \mathrm{l}$, the highest concentration used, and inhibited more bone and liver activity (table 2 ). With specimens containing bone or liver alkaline phosphatase activity as high as $1000 \mathrm{U} / 1$, only $2.0 \%$, $1.3 \%$, and $0.7 \%$ of activity remained after treatment with 5,10 , and $20 \mathrm{mmol} / 1$ levamisole, respectively. In contrast, $75 \%, 62 \%$, and $47 \%$ of intestinal activity remained under the same conditions.

The stability of placental alkaline phosphatase towards levamisole was investigated using serum from

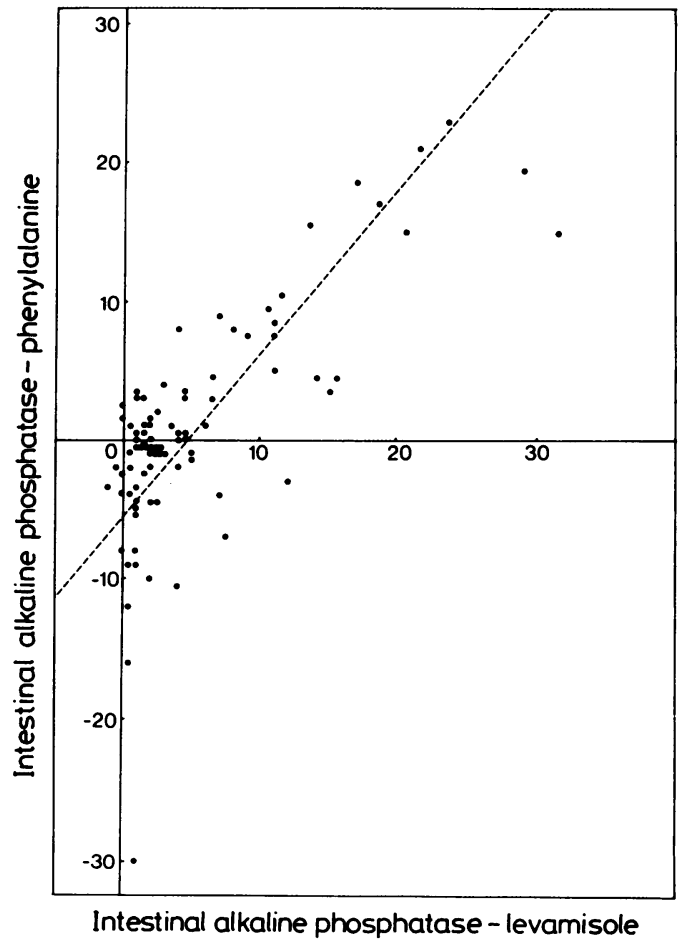

Fig 1 Comparison of intestinal alkaline phosphatase activity in patient specimens. L-phenylalanine or levamisole as inhibitor (total alkaline phosphatase $\leqslant 250 \mathrm{U} / l, n=88$, $r=0.922, y=1 \cdot 185 x-5.5)$. Points not shown: $x, y ; 97$, $95 ; 53,56$. 
Peake, Pejakovic, White

Table 3 Comparison of intestinal alkaline phosphatase (AP) activity in patient specimens using L-phenylalanine (y) or levamisole $(x)$ as inhibitor

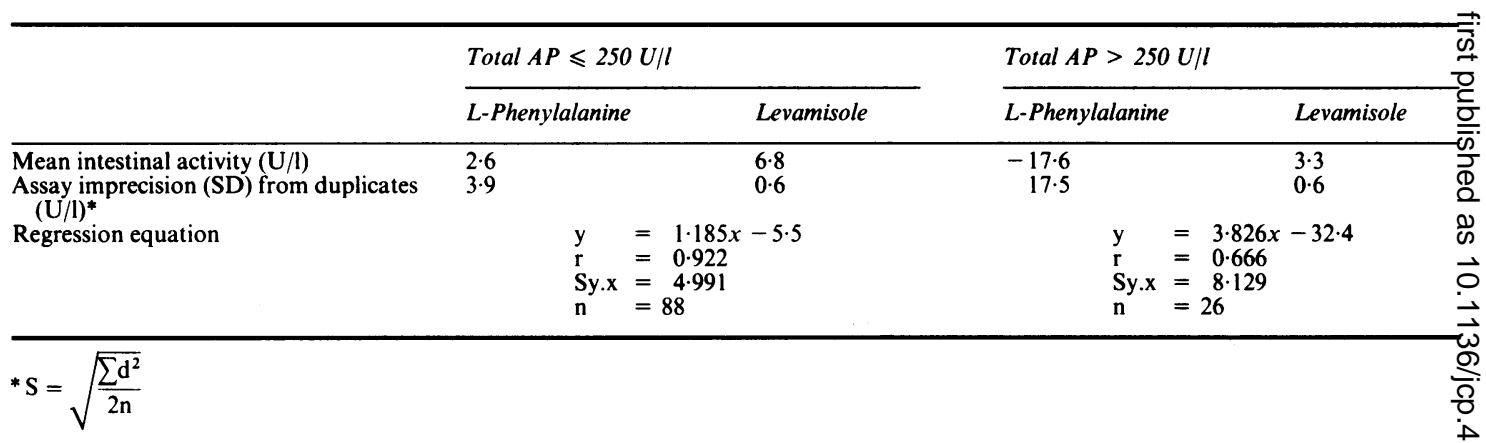

a patient in the 34 th week of pregnancy with a total alkaline phosphatase of $940 \mathrm{U} / 1$ (885 U/1 placental alkaline phosphatase, heat stable for 10 minutes at $\left.65^{\circ} \mathrm{C}\right) ; 54 \%, 39 \%$ and $26 \%$ of activity remained after treatment with 5,10 , and $20 \mathrm{mmol} / \mathrm{l}$ levamisole, respectively. Similar results were found for 15 other sera with placental activity ranging from 50-100 U/l.

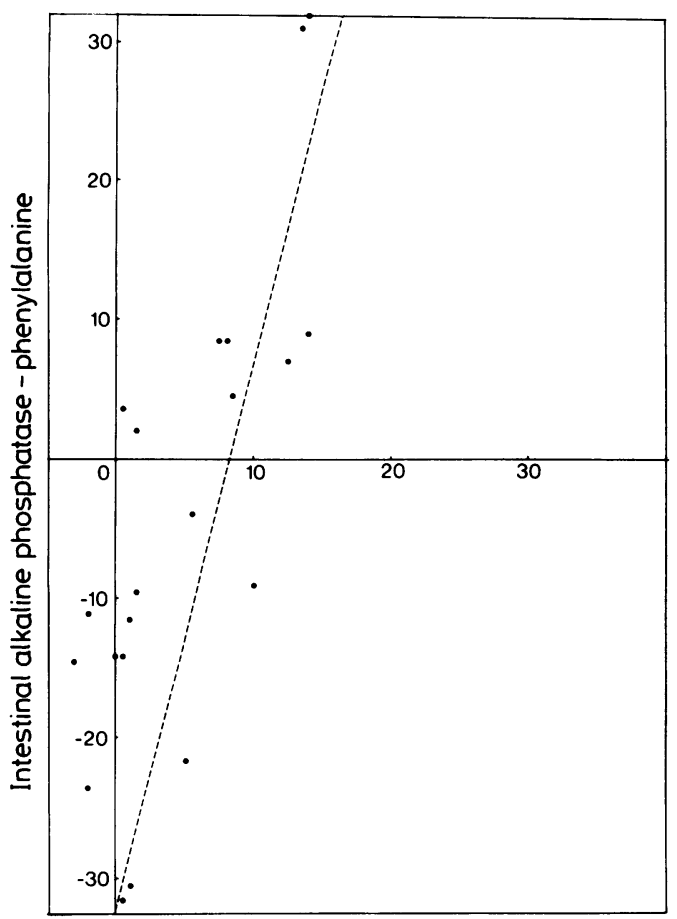

Intestinal alkaline phosphatase - levamisole

Fig 2 Comparison of intestinal alkaline phosphatase activity in patient specimens using $L$-phenylalanine or levamisole as inhibitor (total alkaline phosphatase $>250 \mathrm{U} / \mathrm{l}, n=26$, $r=0.666, y=3.826 x-32.4$. Points not shown: $x, y ; 51$, $41 ;-1,-54 ; 3,-55 ; 1,-56 ;-4,-67$.
Following these experiments levamisole was used for further studies because of its better solubility, easer of preparation, and greater inhibition of non-intestinal components.

\section{LEVAMISOLE COMPARED WITH}

L- PHENYLALANINE

Intestinal alkaline phosphatase activity was measurecov in 114 selected specimens, inhibiting with either $1 \bar{F}^{\mathcal{F}}$ $\mathrm{mmol} / 1$ levamisole or $12.3 \mathrm{mmol} / 1 \mathrm{~L}$-phenylalanine (final concentrations in Cobas rotor $8.1 \mathrm{mmol} / 1$ anc6 $10 \mathrm{mmol} / \mathrm{l}$, respectively). Total alkaline phosphatase activity exceeded $250 \mathrm{U} / 1$ in 26 specimens and $750 \mathrm{U} / \mathrm{Q}$ in five of these specimens. The highest activity was $1850 \mathrm{U} / 1$ in a patient with biliary obstruction. Alp assays were performed in duplicate in separateo analytical runs. With $\mathrm{L}$-phenylalanine, intestinal alk $\stackrel{0}{=}$ aline phosphatase activity was calculated as previouslyğ described. ${ }^{2}$ With levamisole, intestinal alkaline phosphatase activity was calculated using an algorithm derived from the data shown in table 2 .

$$
\mathrm{I}=1.6474 \mathrm{~L}-0.0214 \mathrm{~T}-0.6210 \mathrm{P}
$$

where $\mathrm{I}=$ intestinal activity; $\mathrm{P}=$ placental activity $\mathrm{T}=$ total activity; $\mathrm{L}=$ activity remaining after levamisole inhibition.

Figs 1 and 2 compare results, which are summarise of in table 3.

For specimens with total alkaline phosphatase activity of less than $250 \mathrm{U} / 1$, the mean intestinaE. activity was $2.6 \mathrm{U} / 1$ using L-phenylalanine as inhibitor, and 6.8 U/l using levamisole. Imprecision calculated from duplicate assays was significantly les using levamisole $(\mathrm{SD}=0.6 \mathrm{U} / \mathrm{l})$ than with L-phenylalanine $(\mathrm{SD}=3.9 \mathrm{U} / \mathrm{l})$. For specimens with total activity greater than $250 \mathrm{U} / \mathrm{l}$, many negative results were generated using L-phenylalanine as inhibitor. Additionally, the reproducibility of some of the duplicate assays was poor. In contrast, the stan $\frac{T}{0}$ dard deviation for intestinal activity calculated fromp duplicate assays using levamisole was similar to tha obtained when total activity was less than $250 \mathrm{U} / \mathrm{l}$. 
Table 4 Specimens with intestinal alkaline phosphatase (AP) exceeding $20 \mathrm{U} / \mathrm{l}$ (duplicate analysis)

\begin{tabular}{llll}
\hline Total AP $(U / l)$ & $\begin{array}{l}\text { Intestinal AP }(U / l) \\
\text { Levamisole }\end{array}$ & $\begin{array}{l}\text { Intestinal AP }(U / l) \\
\text { L-Phenylalanine }\end{array}$ & Clinical notes \\
\hline $248 / 239$ & $99(95)$ & $95(95)$ & $\begin{array}{l}\text { Poorly controlled (non)insulin-dependent diabetes mellitus with } \\
\text { metastatic carcinoma of prostate } \\
\text { Congestive cardiac failure, chronic renal failure, multiple drug } \\
\text { treatment }\end{array}$ \\
$156 / 157$ & $53(53)$ & $53(59)$ & $\begin{array}{l}\text { Congestive cardiac failure, analgesic nephropathy, multiple drug } \\
\text { treatment }\end{array}$ \\
$463 / 448$ & $51(50)$ & $47(34)$ & $\begin{array}{l}\text { Chronic renal failure on continuous ambulatory peritoneal dialysis } \\
\text { Insulin-dependent diabetes mellitus + renal transplant }+ \text { multiple } \\
\text { drug treatment }\end{array}$ \\
$161 / 155$ & $31(32)$ & $18(12)$ & $\begin{array}{l}\text { Non-Hodgkin's lymphoma on chemotherapy } \\
\text { Chronic renal failure } \\
105 / 103\end{array}$ \\
$29(29)$ & $19(20)$ & Presumed acute severe multiple sclerosis \\
$228 / 221$ & $24(23)$ & $21(25)$ &
\end{tabular}

Table 5 Comparison of intestinal alkaline phosphatase (AP) activity in serum pools supplemented with intestinal extract using levamisole or L-phenylalanine as inhibitor

\begin{tabular}{|c|c|c|c|c|c|c|c|}
\hline & \multirow[b]{2}{*}{$\begin{array}{l}\text { Added } \\
\text { intestinal } \\
A P\end{array}$} & \multicolumn{6}{|c|}{ Measured intestinal AP $(U / l) *$ (duplicate analysis) } \\
\hline & & $\begin{array}{l}\text { Pool } 1 \\
\text { Total AP } \\
\text { (79 U/l) }\end{array}$ & $\begin{array}{l}\text { Pool } 2 \\
\text { Placental AP } \\
(179 \text { U/l })\end{array}$ & $\begin{array}{l}\text { Pool } 3 \\
\text { Liver AP } \\
\text { (456 U/l) }\end{array}$ & $\begin{array}{l}\text { Pool 4 } \\
\text { Liver AP } \\
(896 U / l)\end{array}$ & $\begin{array}{l}\text { Pool } 5 \\
\text { Bone AP } \\
\text { (361 U/l) }\end{array}$ & $\begin{array}{l}\text { Pool 6 } \\
\text { Bone AP } \\
(877 \text { U/l) }\end{array}$ \\
\hline $\begin{array}{l}\text { Levamisole } \\
\text { Phenylalanine } \\
\text { Levamisole } \\
\text { Phenylalanine } \\
\text { Levamisole } \\
\text { Phenylalanine } \\
\text { Levamisole } \\
\text { Phenylalanine } \\
\text { Levamisole } \\
\text { Phenylalanine } \\
\text { Levamisole } \\
\text { Phenylalanine }\end{array}$ & $\begin{array}{r}176 \\
88 \\
44 \\
22 \\
11 \\
0\end{array}$ & $\begin{array}{r}174(173) \\
162(166) \\
83(81) \\
81(76) \\
45(46) \\
36(43) \\
23(23) \\
21(20) \\
12(12) \\
9(10) \\
2(2) \\
-1(2)\end{array}$ & $\begin{array}{r}174(172) \\
185(180) \\
94(91) \\
93(94) \\
44(41) \\
51(45) \\
22(21) \\
27(20) \\
11(7) \\
13(13) \\
1\left(\begin{array}{l}1 \\
2\end{array}\right) \\
2(6)\end{array}$ & $\begin{array}{r}184(179) \\
162(147) \\
88(88) \\
74(88) \\
43(42) \\
46(42) \\
22(21) \\
8(12) \\
9(10) \\
5(-7) \\
0(1) \\
3(-8)\end{array}$ & $\begin{array}{c}178(174) \\
178(198) \\
87(86) \\
115(59) \\
44(45) \\
21(32) \\
19(21) \\
-9(2) \\
9(11) \\
-12(-4) \\
-2(-2) \\
-8(-39)\end{array}$ & $\begin{array}{r}183(185) \\
176(167) \\
92(92) \\
100(97) \\
44(44) \\
47(40) \\
23(21) \\
7(14) \\
11(11) \\
13(15) \\
-1(-1) \\
-6(-4)\end{array}$ & $\begin{array}{l}188(187) \\
152(209)\end{array}$ \\
\hline
\end{tabular}

*In sera $2 \rightarrow 6$, stated isoenzyme activity represents at least $90 \%$ of total activity.

Of the 114 specimens analysed using levamisole, only eight had intestinal alkaline phosphatase above $20 \mathrm{U} / \mathrm{l}$. The highest activity was $97 \mathrm{U} / 1$ in a poorly controlled diabetic with a metastatic carcinoma of the prostate. Results from other patients in this category are summarised in table 4.

\section{RECOVERY OF INTESTINAL ALKALINE PHOSPHATASE}

To investigate the recovery of intestinal alkaline phosphatase activity intestinal extracts with alkaline phosphatase activities of $11,22,44,88$ and $176 \mathrm{U} / 1$ were added to each of six pools of serum. One of these pools was a normal serum with a total alkaline phosphatase activity of $80 \mathrm{U} / \mathrm{l}$; two further pools contained liver alkaline phosphatase activities of 455 and $900 \mathrm{U} / \mathrm{l}$; another two pools had bone activities of 360 and $880 \mathrm{U} / \mathrm{l}$; the remaining pool had a placental activity of $190 \mathrm{U} / \mathrm{l}$. The intestinal activity recovered from these 30 samples, using either levamisole or Lphenylalanine as inhibitor, is shown in table 5 . Duplicate results obtained for these prepared pools using levamisole had less imprecision than those determined using L-phenylalanine, as was also the case when estimating patient specimens. The latter inhibitor also generated a number of negative results in samples containing low intestinal activities. The errors found using levamisole were in all cases less than $3 \mathrm{U} / 1$ when the added intestinal activity was below $22 \mathrm{U} / \mathrm{l}$, and less than $6 \mathrm{U} / 1$ when the added intestinal activity fell between 22 and $88 \mathrm{U} / 1$.

\section{EFFECT OF HAEMOLYSIS}

When levamisole was used as the inhibitor it was noticed that the reaction rates of some haemolysed sera were less than that for the reagent blank. To investigate this, 10 serum samples with total alkaline phosphatase activity ranging from 40 to $325 \mathrm{U} / 1$ were supplemented with $300 \mathrm{mg} / \mathrm{l}$ of haemoglobin (visual haemolysis). The total alkaline phosphatase activity of each sample uniformly fell by about $8 \mathrm{U} / 1$ in the presence of haemoglobin. An identical fall was evident when L-phenylalanine was used to inhibit intestinal alkaline phosphatase in these specimens, although the 
impact on calculated intestinal activity was small. With levamisole, however, the amount of haemoglobin added was sufficient to render the measured residual activity unreliable, values often being less than that of the reagent blank.

\section{DETECTION LIMIT}

After levamisole inhibition residual serum alkaline phosphatase activity is often less than $20 \mathrm{U} / \mathrm{l}$, even when total activity is high. Depending on the analytical performance of the available equipment, it may be desirable to increase the reaction rate by adjusting sample volume. Using 15 sera with total activity ranging from 75 to $820 \mathrm{U} / 1$, the algorithm produced similar results for sample volumes of 5,10 , and $25 \mu \mathrm{l}$. Thus sample volume can be increased without affecting the calculation of intestinal alkaline phosphatase activity.

\section{Discussion}

Increased intestinal alkaline phosphatase activity has been reported in certain diseases of the digestive tract, ${ }^{5}$ cirrhosis of the liver, ${ }^{6}$ and in patients receiving maintenance haemodialysis. ${ }^{7}$ Another study found that a raised serum intestinal alkaline phosphatase activity in a jaundiced patient suggested an intrahepatic cause. ${ }^{8}$ It has also been reported that decreased amniotic fluid intestinal alkaline phosphatase activity may be indicative of cystic fibrosis.

The contribution to serum total alkaline phosphatase activity by the intestinal isoenzyme is relatively small, even when the enzyme is pathologically increased. It is therefore important that such values are estimated with reasonable accuracy and precision. Use of L-phenylalanine as previously described $^{2}$ resulted in poor duplicate results, and a high incidence of negative values for intestinal alkaline phosphatase activity when total activity was high. The inhibitor levamisole, however, permitted a more direct measurement of intestinal alkaline phosphatase activity and produced positive values with acceptable precision. Levamisole therefore has advantages as an $\overrightarrow{\vec{z}}$ inhibitor for determining intestinal alkaline phos- 을 phatase activity in non-haemolysed serum, and we $\overrightarrow{\vec{F}}$ conclude that this is a useful reagent for the estimation of intestinal alkaline phosphatase activity.

We are grateful to Ms JR Burton for her expert $\frac{\text { D }}{\overparen{D}}$ preparation of this manuscript.

\section{References}

1 Moss DW. Alkaline phosphatase isoenzymes. Clin Chem 1982;28:2007-16.

2 Shephard MDS, Peake MJ, Walmsley RN. Quantitative method $\stackrel{\oplus}{\rightarrow}$ for determining serum alkaline phosphatase isoenzyme activity iN II. Development and clinical application of method for $N$ measuring four serum alkaline phosphatase isoenzymes. 요 J Clin Pathol 1986;39:1031-8.

3 Van Belle H. Alkaline phosphatase. I. Kinetics and inhibition by levamisole of purified isoenzymes from humans. Clin Chem 1976;22:972-6.

4 Shephard MDS, Peake MJ. Quantitative method for determining $\frac{D}{6}$ serum alkaline phosphatase isoenzyme activity I. Guanidine hydrochloride: new reagent for selectively inhibiting major serum isoenzymes of alkaline phosphatase. $J$ Clin Pathol 1986;39:1025-30.

5 Dent CE, Norris TS, Smith R, Sutton RAL, Temperley JM. Steatorrhea with striking increase of plasma alkaline phosphatase of intestinal origin. Lancet 1968;i:1333-6.

6 Stolbach KL, Krant MJ, Inglis NR, Fishman WH. Correlation of serum L-phenylalanine-sensitive alkaline phosphatase derived from intestine with ABO blood group of cirrhotics. Gastroenterology 1967;52:819-27.

7 Walker AW. Intestinal alkaline phosphatase in serum of patients on maintenance haemodialysis. Clin Chim Acta 1974;55: 399-405.

8 Warnes TW, Hine P, Kay G. Intestinal alkaline phosphatase in the diagnosis of liver disease. Gut 1977;18:274-8.

9 Brock DJH, Bedgood D, Barron L, Haywood C. Prospective prenatal diagnosis of cystic fibrosis. Lancet 1985;i:1175-8.

Requests for reprints to: Dr GH White, Department of $\frac{5}{3}$ Biochemistry and Chemical Pathology, Flinders Medical Centre, Bedford Park, South Australia, 5042, Australia. 